\begin{tabular}{cc}
$\begin{array}{c}\text { Yanbu Journal } \\
\text { of } \\
\text { Engineering } \\
\text { and Science }\end{array}$ & Vol. 3, October $2011(1432 \mathrm{H})$ \\
\hline \hline ISSN: $1658-5321$ & www.yjes.org.sa
\end{tabular}

ISSN: $1658-5321$

www.yjes.org.sa

\title{
AN EXPRESS ANALYSIS OF A LOCAL NETWORK CATALOG OF EARTHQUAKES IN THE REGION OF QUETTA, PAKISTAN
}

\author{
Farhana Sarwar Saleem and Saleem Iqbal LalaRukh Kamal
}

Department of Mathematics, University of Balochistan, Quetta, Pakistan

Email: fs1005,saleemiqbal81@yahoo.com

\begin{abstract}
Earthquake catalogs are a valuable result of fundamental seismological practice and they form the basis for seismicity, seismotectonic, seismic risk and hazard investigation. Before one proceed in such investigation it is essential to examine and report on the spatial and temporal homogeneity and completeness of the catalog. As it is well known fact that man made inhomogeneities and artifacts exist in earthquake catalogs that are produced by changing seismological networks. In this paper we are focused on the analysis of local catalog for the region Quetta, of Pakistan, as this region has a history of many large earthquakes. The local catalog considered here is referred from the International Seismological Center (ISC). The catalog contains information from 0101-1992 to 30-06-2006. The catalog covers an area Latitude 28.00 to $32.00 \mathrm{o} \mathrm{N}$, Longitude 65.00 to $69.00 \mathrm{o}$ E and contains 690 events. To examine and report on the spatial and temporal homogeneity and completeness of the local catalog its comparison is done with the Global Catalog of National Earthquake Information Center (NEIC) of USA. Finally to get a homogeneous catalog for the region, we merge the two catalogs by considering different data properties and different data analysis techniques prepared by different data collection agencies. The merged catalog is rather homogeneous as variation in the completeness of the catalogs is reduced. The merged catalog is reliable for the applications of different earthquake Prediction techniques.
\end{abstract}

Keywords: Earthquake Catalog, Frequency Magnitude Relation, Power Law.

\section{INTRODUCTION}

The Quetta region has a history of the many large earthquakes and is at high seismic risk. This seismic activity is due to the movement along the active faults in the region. The Chaman fault is the main structure in this region. It is a left lateral wrench fault and is traced on the map for about $320 \mathrm{~km}$ along an approximate north-south orientation from latitude $27^{\circ}$ to $30^{\circ} \mathrm{N}$ and extends northwards into Afghanistan for another $240 \mathrm{~km}$ [1]. It is the most significant tectonic feature of
Pakistan, specifically in the Quetta region. The Chiltan-Takhatu faults are the other two main active thrust faults in the region. These faults pass with almost north-south orientation in the west of the Quetta Valley. There also exist some active faults and lineaments in the eastern mountains of the valley.

For complete investigation about seismicity, seismotectonic, seismic risk and hazard analysis in the region, it is essential to examine and report on the spatial and temporal homogeneity and completeness of the 
Earthquake catalog. It is a common knowledge that catalogs have errors, whose identification and elimination is desirable [2]. It suffers from the three types of man-made seismicity changes identified in $[3,4,5]$, namely detection changes, reporting changes, and magnitude shifts. These errors can also be distinguished into systematic and random ones and in 1995 this is comprehensively discussed by Kossobokov in [6]. Systematic errors can be associated with changes in the data acquisition system or in the methods for the determination of earthquake parameters. Random errors correspond generally to the uncertainty of determination and to possible mistakes made during data input process.

Most of the errors could not be corrected without reference to the original source records. However many of them could be detected when two or more catalog sources available. It is necessary to compare catalog available for equivalent and nonequivalent entries, and to compare values of parameters (e.g. magnitudes) from different sources.

\section{DATA}

In this paper we have considered two catalogs of earthquakes to analysis and report on the spatial and temporal homogeneity and completeness of the catalog, the local catalog prepared by Micro Seismic studies Program (MSSP) and the Global Catalog prepared by the National Earthquake Information Center Global Hypocenter data base of the US Geological Survey (USGS/NEIC GHDB).

\subsection{Quetta local Catalog of EarthQuakes}

The observations made in the Quetta local catalog of earthquakes have been made by the Micro Seismic studies Program (MSSP) based in Islamabad, Pakistan. MSSP has been providing phase data to International Seismological Center (ISC) since January 1984, the objective of this cataloging has been to provide the original phase data. Although the data set reports more seismic events than NEIC GHDB, but it is lacking determination of magnitude $\left(M_{s}\right.$ in particular). The catalog contains information from 01-011992 to 30-06-2006 covering an area Latitude 28.00 to $32.00^{\circ} \mathrm{N}$, Longitude 65.00 to 69.00 ${ }^{\circ} \mathrm{E}$ and contains 690 events.

\subsection{NATIONAL EARTHQUAKE INFORMATION CENTER GLOBAL HYPOCENTERS OF Database OF THE US Geological SurVey.}

Earthquake catalog prepared by the National Earthquake Information Center Global Hypocenter Data base of the US Geological Survey (USGS/NEIC GHDB) is found very reliable and complete for magnitude $\mathrm{M} \geq 4.0$ from 1964 onward. When the World Wide Seismic Station Network (WWSSN) of USGS became operational. From the global catalog of NEIC a Sub-catalog is obtained for Quetta, Pakistan.

\section{RESULTS AND DISCUSSION}

In this paper we have done a comparison, data analysis and merging of two catalogs Quetta local catalog and NEIC by using computer programs like CompiCat [7], Microsoft Excel and Seismic Eruption to get a rather homogeneous catalog. The purpose of analysis and merging of the two catalogs is to extract useful information as discussed below. The comparison gives a better understanding to avoid catalog errors and uncertainties as they render invalid conclusion derived from a study based on a catalog of earthquakes. In this paper we have used different presentation techniques for analysis which includes plots of seismicity, time versus magnitude, and the Gutenberg-Richter relationship and Histograms of differences.

\subsection{TIME DisTRIbUTION OF EARTHQUAKES}

Earthquakes occur randomly in time. A frequency magnitude relation shows the 
number of earthquakes per year and one can observe the completeness of the catalog. Fig.1 is showing the number of earthquakes per year according to the Quetta catalog. The catalog is quite complete for smaller magnitudes 3.0-4.0 but for larger magnitudes 4.5 to 6.5 the catalog is incomplete. Fig. 2 shows a frequency magnitude graph from the USGS / NEIC GHDB catalog.

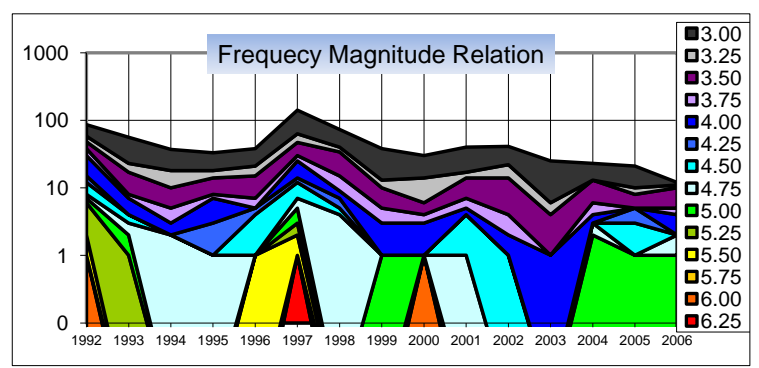

Fig.1. The number of earthquakes per year from Local catalog

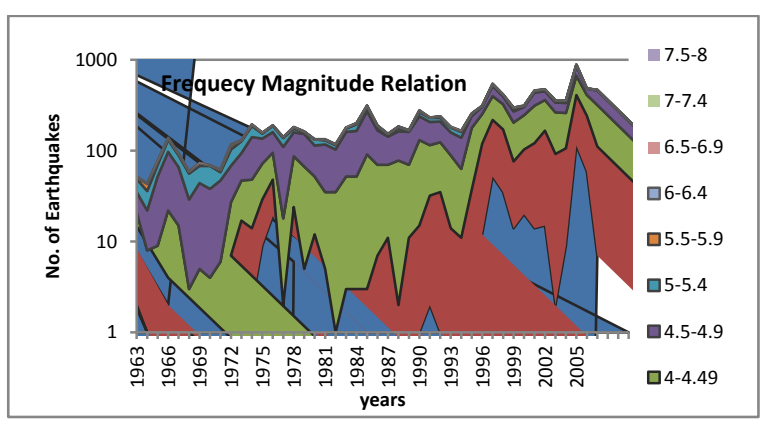

Fig.2.Frequency magnitude relation for USGS/NEIC GHDB catalog

It is obvious from Fig. 2 that no record of magnitude 3.00-3.99 before 1991.Also for higher magnitudes 5.0-6.5 the catalog is not complete. For magnitudes 4.00-4.99 the catalog shows quite good completeness.

By observing the frequency magnitude relation of the two catalogs as in Fig. 1 and Fig.2 we have merged the two catalogs to get a catalog with the quite good completeness of magnitude range from 3.00 to 4.99 for the region.

\subsection{DIFFERENCE OF HYPOCENTER}

Fig. 3 Epicenters of earthquakes reported in USGS/NEIC GHDB (left) and the Quetta Local Catalog (right). Note the evident deficiency of the aftershocks of the 1997, M 6.2 major event, as well as many small magnitude earthquakes on the right plate of the figure. The size of the dots indicates the magnitude and colour of the dots indicate the depth of the earthquake

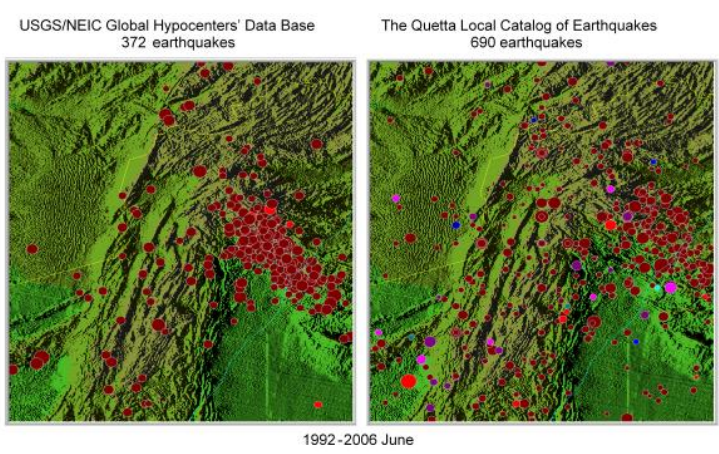

Fig. 3. Epicenters of earthquakes reported in USGS/NEIC GHDB (left) and the Quetta Local Catalog (right)

Figure3 permits making the first evident observation. On the one hand, there are many small (about magnitude 3 or larger) and a few larger (up to magnitude 5.6) events that have no match in the USGS/ NEIC GHDB. On the other hand, most of the aftershocks of the 1997 M 6.2 earthquake are absent in the local catalog. Apparently the local network was not recording at least in the first few days after this major earthquake.

\subsection{SIZE DISTRIBUTION OF EARTHQUAKES}

The size distribution of earthquakes has been found to show a power law behavior. When plotted in a logarithmic plot, the distribution is linear. This was first recognized by Ishimoto and Lida [8] in Japan and Gutenberg and Richter [9], introduced the common description of the frequency of earthquakes:

$\log _{10} N=a-b \mathrm{M}$ 
Where $\mathrm{N}$ is the cumulative number of earthquakes, $M$ is the magnitude, $a$ and $b$ are constants. The constant $a$ reflects the absolute level of seismicity of the region and the constant $b$ has been found to be consistently close to the value 1 . This relationship has been found to apply to particular regions as well as to the world as a whole

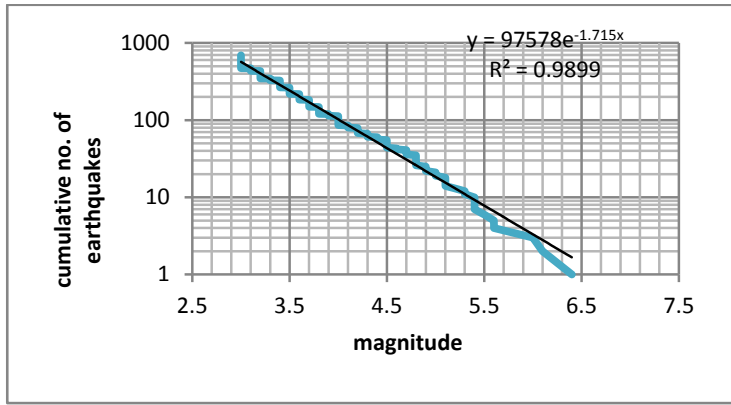

Fig. 4 The Quetta Local Catalog of earthquakes. The Gutenberg-Richter plot

As could be judged from Fig.4, a systematic, although evidently far from complete, record of earthquakes in the local catalog show up a near perfect linear plot of the Gutenberg Richter relationship down to magnitude 3.0 (the R-squared statistic equals about 99\%) while the $b$-slope value $(b=0.7448)$ may indicate either an underestimation of small magnitude events or as an alternative a subcritical regime with an excess of larger magnitude events in the seismic region considered. This kind of consistency of the local catalog and reasonable completeness of the USGS/ NEIC GHDB at the magnitude level about 5 suggests combining the two data sources for a better characterization of seismic activity in the vicinity of Quetta. The combined catalog contains 1095 records from 1992 to the middle of 2006 and covers the territory between $27^{\circ} \mathrm{N}-33^{\circ} \mathrm{N}$, and $63.5^{\circ} \mathrm{E}-$ $70.5^{\circ} \mathrm{E}$. This is the initial data source of further analysis.

\subsection{HiSTOGRAMS OF DIFFERENCES}

In order to perform the comparison between the two catalogs a sub catalog of the equivalent catalog records is obtained. Two records from the two catalogs are considered as records of the same event if the difference in their hypocentral coordinates; time and magnitude do not exceed a set of predefined thresholds, i.e. if they satisfy the following conditions according to $[10,11]$

- Time = 1 minute

- Longitude $=0.5^{0}$

- Latitude $=0.5^{\circ}$

- Depth = not limited

- Magnitude $=$ not limited

Difference in Magnitude

$\mathrm{mb}$

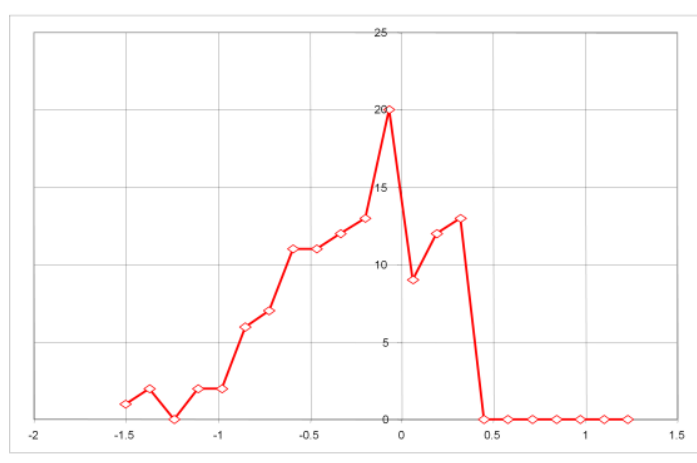

MS

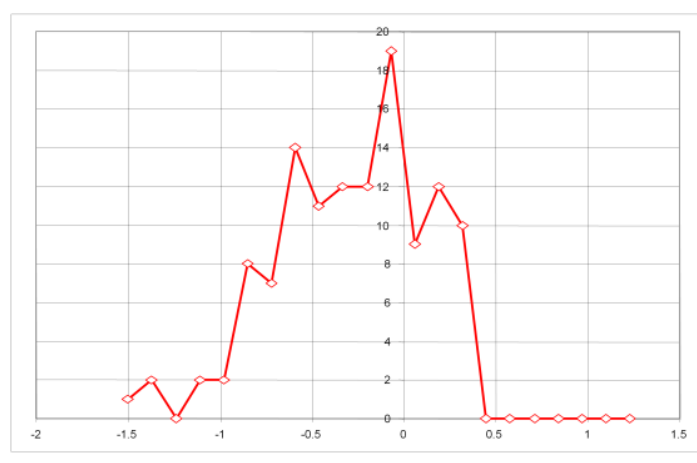

Fig. 5 Difference of magnitude between the two catalogs

Figure 5 shows a substantial difference in the magnitudes reported in the USGS/NEIC GHDB and the Quetta Local Catalog. The analysis is performed by evaluating for a fixed 
type of magnitude the quantities $\Delta \mathrm{M}=\mathrm{M}_{\text {Quetta- }}$ $\mathrm{m}_{\mathrm{b}}$ and $\Delta \mathrm{M}=\mathrm{M}_{\text {Quetra }^{-}} \mathrm{M}_{\max }$ which are differences between magnitude of same type reported in the two catalogs for each of the common earthquake, where $m_{b}$ and $M_{\max }$ is the body wave magnitude and maximum of the values reported in the USGS/NEIC GHDB for the event respectively. [In general, the USGS/NEIC GHDB may report up to the four estimations of magnitude for each single event: the average surface wave magnitude $M_{s}$ and the average body wave $m_{b}$ (both computed from the reported determinations from seismographic stations), along with the values of so-called authority magnitudes $M_{1}$ and $M_{2}$, which correspond to the magnitude determinations contributed by different agencies, e.g., before 1993 the surface wave magnitudes computed in Berkley and Pasadena were dominant, since 1993 these are usually the moment magnitudes from Harvard and USGS.]

The comparison of the catalogs for equivalent events shows that when the location uncertainty is set to one half of a degree, there are just 44 pairs of equivalent records present both in the global and in the local data sets. This number rises to 142 pairs, when the location uncertainty is increased to one degree. Still it is a tiny portion of the total in either of the data sets.

Figures 6, 7, 8 and 9 are showing the uncertainty in location according to the differences of epicenter parameters of the equivalent catalog records. These location uncertainties are caused by measurements errors and by the unfavorable geometry of stations that recorded the earthquake. The combination of both factors leads to scatter in the earthquake locations that may be quite complicated. . Uncertainties in earthquake locations can also be introduced due to errors in station parameters (location, timing), due to misidentification of seismic phases, and due to errors in the velocity model used to compute the earthquake locations. In general, these errors lead to a systematic bias in earthquake locations and, hence, they affect the accuracy of an earthquake location. If the measurement errors are known a prior, these location uncertainties can be adequately computed using modern location techniques Histograms of the differences in latitude (Fig.6), longitude (Fig.7), depth (Fig.8), and the map of epicenter misfit indicate a substantial degree of uncertainty in locating earthquakes in the vicinity of Quetta, the distributed bias in location of epicenters due to the limited area of the local network sites, in particular (Fig.9).

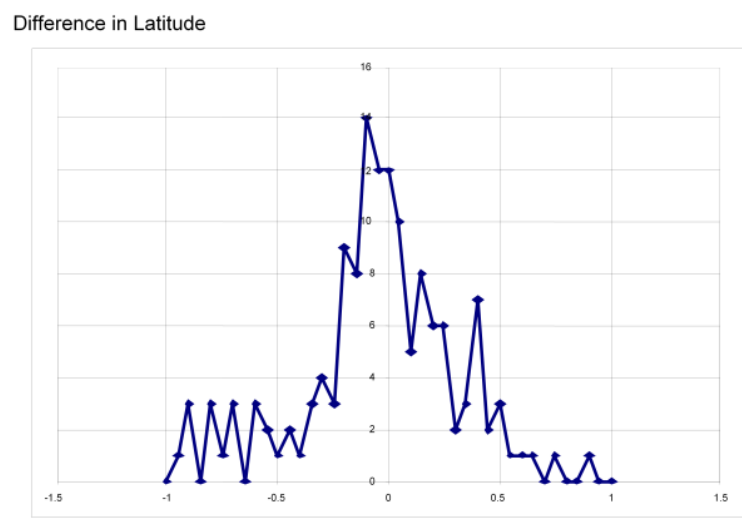

Fig.6. Showing difference in latitude for the equivalent entries of the two catalogs.

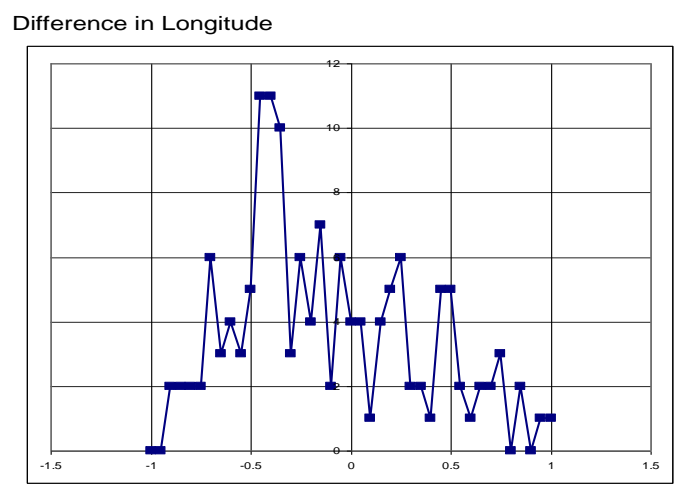

Fig.7. Showing difference in longitude for the equivalent entries of the two catalogs 


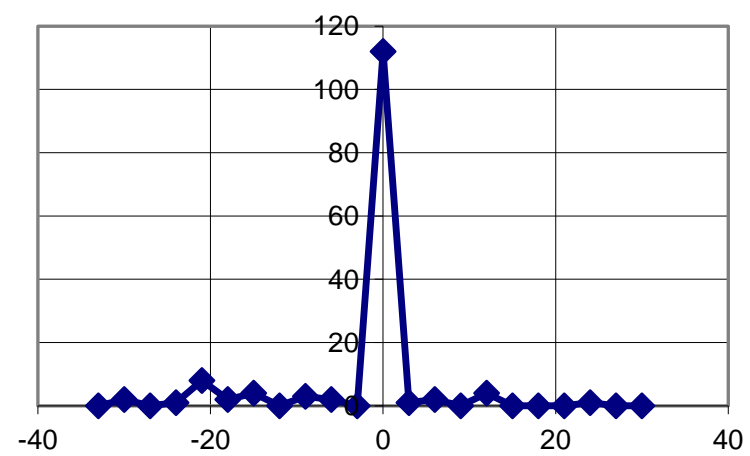

Fig. 8. Showing difference in depth for the equivalent entries of the two catalogs

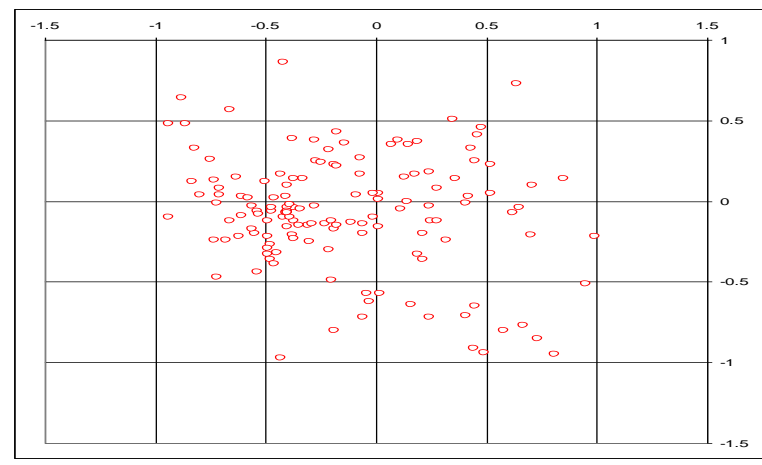

Fig. 9. This figure shows the uncertainty in location according to the difference of hypocenter parameters of the equivalent catalog record

\section{CONCLUSION}

The analysis of Quetta local catalog data shows that events with $M 3.0$ are recorded and there is no evidence of $M<3.0$. The existing local catalog can be considered complete for magnitudes 3.0 - 4.0.The catalogue USGS/NEIC GHDB is essentially incomplete, within the analyzed territory, for magnitudes lower than 4.0 but for magnitudes 4-4.99 it is complete. On the basis of this kind of consistency of the local catalog as observed by the Gutenberg Richter relation and reasonable completeness of the USGS/NEIC GHDB at the magnitude level about 5 the two data sources are merged for a better characterization of seismic activity in the vicinity of Quetta. The combine catalog contains 1095 records from 1992 to the middle of 2006 and covers the territory between Latitude $27^{0} \mathrm{~N}-33^{\circ} \mathrm{N}$ and Longitude $63.5^{0} \mathrm{E}-70.5^{\circ} \mathrm{E}$. This is the initial data source for further analysis. The merged catalog is rather homogeneous as variation in the completeness of the catalogs is reduced. The merged catalog is reliable for the application of different earthquake Prediction techniques.

\section{REFERENCES}

[1] Kazmi A. H. "Active Fault System in Pakistan". Geodynamics of Pakistan by Farah, A. \& DeJong, K. E (editors), Geological Survey of Pakistan, Quetta, 1979, pp.285-294.

[2] Peresan V. kossobokov L. Romashkova and G.F Panza "Intermediate term middle range earthquake predictions in Italy: a review" EarthSciences vol.69, 2005, pp. 97-132.

[3] R.E. Habermann, "Man made changes of seismicity rates" Bulletin of the Seismology Society of America, Vol. 77, 1987, pp.141-159

[4] F.R. Zuniga,and S.Wiemer,"Seismicity patterns: are they always related to natural causes ?",Pure and Applied Geophysics,Vol.155,1999,pp 713726.

[5] R.Zuniga, and M.Wyss, Inadvertent changes in magnitude reported in earthquake catalogs:Influence on b-value estimates", Bulletin of the Seismological Society of America, Vol. 85,1995,pp 1858-1866.

[6] V.G. Kossobokov "Analysis of earthquake catalogs" In Preceding of the third Workshop on Non-linear Dynamics and Earthquake Prediction. International Center for Theoretical Physics, Trieste, Italy, 1995.

[7] V.G. Kossoboko, A. Mostinskiy and P Shebalin, "CompiCat Programme,"2007 http://www.mitp.ru/soft/ecp/doc/mainindex. Html.

[8] M. Ishimoto and K.Iida," Observations of earthquakes registered with the microseismograph constructed recently", Bulletin of Earth quakes. Research Institute, Vol.17, 1939, pp 443-478.

[9] R. Gutenberg and C.F.Richter, "Frequency of earthquakes in California", Bulletin of the Seismological Society of America, Vol.34, 1944,pp. 185-188.

[10] M. Rosa, A. Peresan, L.L Romashkova, G.F Panza, and M. Herak, "The Adria catalogue: a 
unified catalogue of earthquakes for the Adriatic Sea and surrounding regions Preprints, The Abdus Salam ICTP,Trieste,Italy 2006

[11] D.A Storchak,A.L.Bird and R.D Adams "Location Discrepancies", XXVI General Assembly of ESC, Tel Aviv, Israel 1998. 


\title{
تحليل دقيق لثبكة الزلازل المحلية في منطقة كوتيا في الباكستان
}

\author{
فرحانا ساروار سليم، وسليم إقبال كمال \\ قسم الرياضيات، جامعة بلوشتان، كويتا، الباكستان
}

الملخص:

إن كاتالوجات الزلازل تعتبر معلومات قيمه حيث تثكل أساساً لعمليات التنبؤ بخطر وقوع الزلازل. ولتحقيق ذلك فمن الضروري أن ينم إختيار مدى التجانس و التكامل الزماني و المكاني لكتالوجات الزلازل بسبب التغيرات

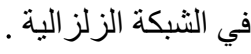

في هذا البحث تم التركيز على تحليل الكتالوج المحلي للزلازل في منطقة كويتا في الباكستان حيث أن هذه المنطقة معروفة تاريخياً بتعرضها لزلازل قوية. إن هذا الكتالوج المحلي يعود إلى مركز الزلازل الدولي حيث أن هذا الكتالوج يحتوي على معلومات في الفترة من 1992/1/1 إلى 2006/6/30 وهو يغطي مناطق خط العرض 65 إلى 69 درجة شرقاً.

ولتحليل وإختيار مدى التجانس والتكامل لهذا الكتالوج الزلاز الي المحلي تم مقارنته بالكتالوج الزلزالي الدولي الصادر من مركز معلومات الزلازل الوطني بالولايات المتحدة الأمريكية، وللحصول على كتالوج زلزالي متجانس للمنطقة تم دمج الكتالوجين، آخذاً بعين الإعتبار تقنيات تحليل النتائج والتي تم الحصول عليها بواسطة من وسائط مختلفة لجمع المعلومات. إن الكتالوج الناتج يعتبر متجانساً ويمكن الإعتماد عليه للتنبؤ بالز لازل.. 